\title{
NEONATAL 6-HYDROXYDOPAMINE TREATMENT ELIMINATES CHOLINERGIC SYMPATHETIC INNERVATION AND INDUCES SENSORY SPROUTING IN RAT SWEAT GLANDS ${ }^{1}$
}

\author{
MARILYN L. YODLOWSKI, JOHN R. FREDIEU, AND STORY C. LANDIS ${ }^{2}$ \\ Department of Neurobiology, Harvard Medical School, Boston, Massachusetts 02115 \\ Received June 1, 1983; Revised December 29, 1983; Accepted January 4, 1984
}

\begin{abstract}
Previous studies of the development of cholinergic sympathetic innervation of sweat glands in rat footpads suggested that these terminals initially exhibit noradrenergic properties which are lost as the glands and their innervation mature. We have treated neonatal and adult rats with 6hydroxydopamine (6-OHDA), a toxic congener of norepinephrine, and compared its effects on the cholinergic sympathetic innervation of sweat glands and the noradrenergic sympathetic innervation of the iris, salivary gland, and blood vessels. As reported by others, 6 -OHDA treatment of neonates caused the destruction of noradrenergic fibers in the iris and salivary gland but did not affect other fibers projecting to these targets that stain for acetylcholinesterase (AChE). We found that 6OHDA treatment of neonatal animals also caused the destruction of the sympathetic axons in immature sweat glands that possess catecholamine histofluorescence and tyrosine-hydroxylase-like immunoreactivity. Furthermore, when such animals were examined as adults, we found no AChE staining, vasoactive intestinal peptide (VIP)-like immunoreactivity, or characteristic sympathetic axonal varicosities. However, the denervated glands were invested by a plexus of sensory axons, some of which exhibited substance P-like immunoreactivity (SP-IR). An increase in the number of SP-IR fibers also occurred in the sympathetically denervated irides of these animals. Chronic treatment of neonates with guanethidine, another adrenergic sympathetic neurotoxin, resulted in similar loss of cholinergic sweat gland innervation. Treatment of adult rats with doses of 6-OHDA identical to those used to treat neonates caused the loss of noradrenergic fibers from the iris, salivary gland, and many blood vessels but did not noticeably affect $\mathrm{AChE}$ and VIP staining or axonal ultrastructure in the sweat glands. However, treatment with higher doses of 6-OHDA did cause significant axonal degeneration. The response of the sympathetic innervation of developing but not mature sweat glands to 6-OHDA provides evidence for a transition from noradrenergic to cholinergic phenotype during the development of sympathetic neurons in vivo similar to the transition observed in cell culture. The sprouting of sensory axons may be caused by NGF-like trophic influences present in some sympathetically denervated tissues.
\end{abstract}

Most principal sympathetic neurons are noradrenergic. A minority, including those which innervate eccrine sweat glands concentrated in footpads of cats and rats, are cholinergic. Examination of the sweat gland inner-

\footnotetext{
${ }^{1}$ This work was supported by United States Public Health Service Grants NS 15549 and NS 02253 from the National Institute of Neurological and Communicative Disorders and Stroke. This work was done during the tenure of an Established Investigatorship of the American Heart Association (S. C. L.) and with funds contributed in part by the Massachusetts Affiliate. We wish to thank Patrick Hogan for the vasoactive intestinal peptide antiserum, Edwin Furshpan, Paul Patterson, David Potter, and our other colleagues for helpful discussion and Shirley Wilson for help with the manuscript.

* To whom correspondence should be addressed.
}

vation in developing and adult rats has uncovered several unusual properties (Landis and Keefe, 1983). First, during development, the axons associated with the immature glands possess several cytochemical properties associated with noradrenergic function, including catecholamine histofluorescence and small granular vesicles (SGV) after permanganate fixation. These catecholaminergic properties disappear as the glands and their innervation mature. Second, the axons in the adult innervation, which do not contain detectable endogenous catecholamine, can take up and store some exogenous catecholamine. These observations suggested that noradrenergic axons innervated the developing sweat glands but then lost their stores of endogenous catecholamines as they 
elaborated an axonal plexus in the maturing glands. More generally, these observations raise the possibility that some cholinergic sympathetic neurons undergo a transition from noradrenergic to cholinergic function during development in vivo similar to that described in cell culture. (M. Johnson et al., 1976, 1980; Patterson, 1978; Landis, 1980; Potter et al., 1981).

We have used the toxic catecholamine congener 6hydroxydopamine (6-OHDA) to obtain further evidence for the presence of noradrenergic properties in developing cholinergic sympathetic neurons. 6-OHDA is taken up selectively by catecholaminergic neurons. In adult animals, it causes the destruction of peripheral noradrenergic nerve terminals but not cell bodies (Thoenen and Tranzer, 1968; De Champlain, 1971; Clark et al., 1972; Finch et al., 1973). However, when administered to neonatal rats and mice, 6-OHDA causes the destruction of peripheral noradrenergic nerve terminals and also cell bodies, resulting in a near-total chemical sympathectomy (Angeletti and Levi-Montalcini, 1970; Angeletti, 1971; Jaim-Etcheverry and Zieher, 1971; Clark et al., 1972; Finch et al., 1973). We reasoned that if the developing sweat gland innervation was initially noradrenergic and became cholinergic, as our ultrastructural observations suggested, then 6-OHDA treatment of newborns would eliminate the sweat gland innervation while treatment of adults should not. However, if the glands were innervated by two populations of axons, one noradrenergic, that was later lost, and one cholinergic, that was retained, then neither neonatal nor adult 6-OHDA treatment should eliminate completely the sweat gland fibers. In addition, we chronically treated neonatal rats with guanethidine which, like 6-OHDA, causes chemical sympathectomy (Burnstock et al., 1971; Eränkö and Eränkö, 1971; Johnson and O'Brien, 1976; Herskovits and Singh, 1982; Manning et al., 1983).

\section{Materials and Methods}

Litters of newborn and adult rats were obtained from Charles River (CD strain, Wilmington, MA). Experimental animals received intraperitoneal injections of $100 \mathrm{mg} /$ $\mathrm{kg}$ of 6-OHDA (Sigma Chemical Co., St. Louis, MO) dissolved in physiological saline $(0.85 \% \mathrm{NaCl})$ with 0.5 $\mathrm{mg} / \mathrm{ml}$ of ascorbic acid to retard oxidation of the drug. Control animals received injections of the vehicle solution only. Rat pups were injected on days 1 to 7 and day 12 after birth. Animals treated as neonates were killed at 7 and 14 days, 4 weeks, 2 months, and 5 months after birth. Similar protocols have been shown to result in the loss of the catecholamine stores in heart and salivary gland (Clark et al., 1972; Finch et al., 1973). Identical dosages and sequences of 6-OHDA or control injections were given to adult rats ( 150 to $300 \mathrm{gm})$. These animals were killed and examined 2 weeks after the injections. In addition, six adult rats were injected with higher doses of 6-OHDA, $200 \mathrm{mg} / \mathrm{kg}$ twice a day. Three animals were killed after three injections, and their irides and footpads were examined with the electron microscope after aldehyde-osmium fixation. Three animals were killed after 14 injections, and their footpads were examined with the electron microscope after aldehyde-osmium fixation. In total, more than 60 animals injected as neonates and 30 animals treated as adults were examined.
One litter (10 pups) of newborn rats was treated with guanethidine. The animals were injected intraperitoneally 5 days/week for 6 weeks with $50 \mathrm{mg} / \mathrm{kg}$ of guanethidine sulfate (Ismelin, CIBA) in saline. These animals were examined 8 weeks after the initiation of injections.

Procedures for formaldehyde-induced fluorescence, AChE staining, and the ultrastructural studies have been described in detail previously (Landis and Keefe, 1983). In brief, submandibular salivary glands, hind footpads, and irides were prepared for catecholamine histofluorescence according to the Falck-Hillarp technique. For AChE staining, cryostat sections of footpads and salivary glands and stretch preparations of iris were briefly fixed with $1 \%$ paraformaldehyde and $1.25 \%$ glutaraldehyde in phosphate buffer, rinsed, and processed using the KarnovskyRoots procedure. For light and electron microscopy, rats were perfused transcardially with fixative containing $2 \%$ paraformaldehyde and $2.5 \%$ glutaraldehyde in phosphate buffer. In some experiments, rats were perfused with $4 \%$ paraformaldehyde in phosphate buffer, and the pads from one foot were further fixed for electron microscopy by immersion in $2 \%$ paraformaldehyde and $2.5 \%$ glutaraldehyde, whereas pads from the other foot were used for immunocytochemical staining. Footpad slices were postfixed with osmium tetroxide, stained en bloc with uranyl acetate, dehydrated, and embedded in Epon. One-micrometer plastic sections were stained with toluidine blue and thin sections with lead citrate.

Tyrosine hydroxylase-like(TH-IR), vasoactive intestinal peptide-like (VIP-IR), somatostatin-like, and substance P-like (SP-IR) immunoreactivities were examined with immunocytochemical techniques in footpads, irides, and tongue. To examine footpads and tongue, rats were perfused with $4 \%$ paraformaldehyde in $0.1 \mathrm{M}$ phosphate buffer, $\mathrm{pH} 7.3$, for $10 \mathrm{~min}$. The hind footpads and tongue were removed and left in the fixative solution for $1 \mathrm{hr}$, rinsed in $0.1 \mathrm{M}$ phosphate buffer, and equilibrated with $30 \%$ sucrose in $0.1 \mathrm{M}$ phosphate buffer overnight. Tenmicrometer cryostat sections were mounted on gelatincoated slides. To examine irides, the unfixed iris was stretched onto a gelatin-coated slide, allowed to dry partially, immersed in $4 \%$ paraformaldehyde for $60 \mathrm{~min}$, and then rinsed extensively with phosphate buffer. Slides were rinsed with phosphate-buffered saline (PBS) and incubated with rabbit antisera to VIP (1:500 dilution), to substance $\mathrm{P}(1: 250)$, to somatostatin $(1: 100)$, or to $\mathrm{TH}$ (1:1000) in humid chambers at $21^{\circ} \mathrm{C}$ for 16 to $20 \mathrm{hr}$. Following incubation, the sections were rinsed with PBS and incubated for $2 \mathrm{hr}$ at room temperature with tetramethylrhodamine isothiocyanate-conjugated goat antirabbit immunoglobulin (Cappel, Cochranville, PA). The sections were rinsed again with PBS $(3 \times 10 \mathrm{~min})$, mounted in glycerol:ethanol (1:1), and examined with a Zeiss microscope equipped with epifluorescence and a rhodamine filter set. All incubations with antisera were carried out in a solution containing $0.5 \mathrm{M} \mathrm{NaCl}, 0.01 \mathrm{M}$ phosphate buffer, $\mathrm{pH} 7.3,0.2 \%$ Triton $\mathrm{X}-100,0.1 \%$ sodium azide, and $5 \%$ bovine serum albumin (BSA, Sigma Chemical Co.).

The VIP antiserum used in these experiments was prepared in rabbits with a carbodiimide conjugate of synthetic VIP (Boehringer-Mannheim, Indianapolis, IN) (Fahrenkrug and Shaffahtsky de Muckadell, 1977) with 
BSA. The substance $\mathrm{P}$ and somatostatin antisera were obtained from Immunonuclear (Stillwater, MI). The TH antiserum was a gift from Dr. J. Thibault of the College de France, and its properties have been described elsewhere (Thibault et al., 1981). No staining was observed if normal rabbit serum was substituted for the primary antisera or if the VIP, substance P, or somatostatin antisera were pre-incubated with $10 \mu \mathrm{g} / \mathrm{ml}$ of the appropriate synthetic peptide (Boehringer-Mannheim).

\section{Results}

Treatment of neonatal rats. To assess the effectiveness of our 6-OHDA treatments, we examined the sympathetic and parasympathetic innervation of the iris and salivary glands of adult animals that had been treated as neonates. In normal rats, a dense network of sympathetic, catecholamine histofluorescent fibers was present in the iris (Fig. 1a) and submandibular salivary gland. AChE staining also revealed an axonal plexus in the iris and salivary gland (Fig. 1c). The AChE reflects principally parasympathetic innervation since in the iris the staining disappears after ciliary ganglionectomy (Ehinger, 1966) and in the salivary gland the staining is not affected by sympathectomy (Snell and Garrett, 1958; Freitag and Engel, 1970). Neonatal treatment of animals with 6-OHDA resulted in the virtually complete absence of catecholamine fluorescent fibers from both salivary gland and iris in rats examined as adults (Fig. $1 b$ ), but it did not affect the pattern or intensity of the AChE staining in these tissues (Fig. $1 d$ ).

We examined the effects of neonatal 6-OHDA treatment on the cholinergic sympathetic innervation of sweat glands in the footpads of both developing and adult animals. In normal animals at 7 and 14 days, the fibers in the sweat glands possess catecholamine histofluorescence (Landis and Keefe, 1983) and TH-IR (Siegel et al., 1982) (Fig. 2, $a$ and $c$ ); after 21 days, the sweat gland fibers can be identified reliably with the light microscope by prominent $\mathrm{AChE}$ staining and immunoreactivity for VIP (Fig. 2, $e$ and g). However, in the 6-OHDA-treated rats, no catecholamine histofluorescence or TH-IR (Fig. $2, b$ and $d$ ) was evident in the developing sweat glands at 7 and 14 days, and no AChE or VIP-IR was evident in the mature sweat glands (Fig. 2, $f$ and $h$ ).

When the sweat gland innervation of normal adult rats is examined with the electron microscope, bundles of 8
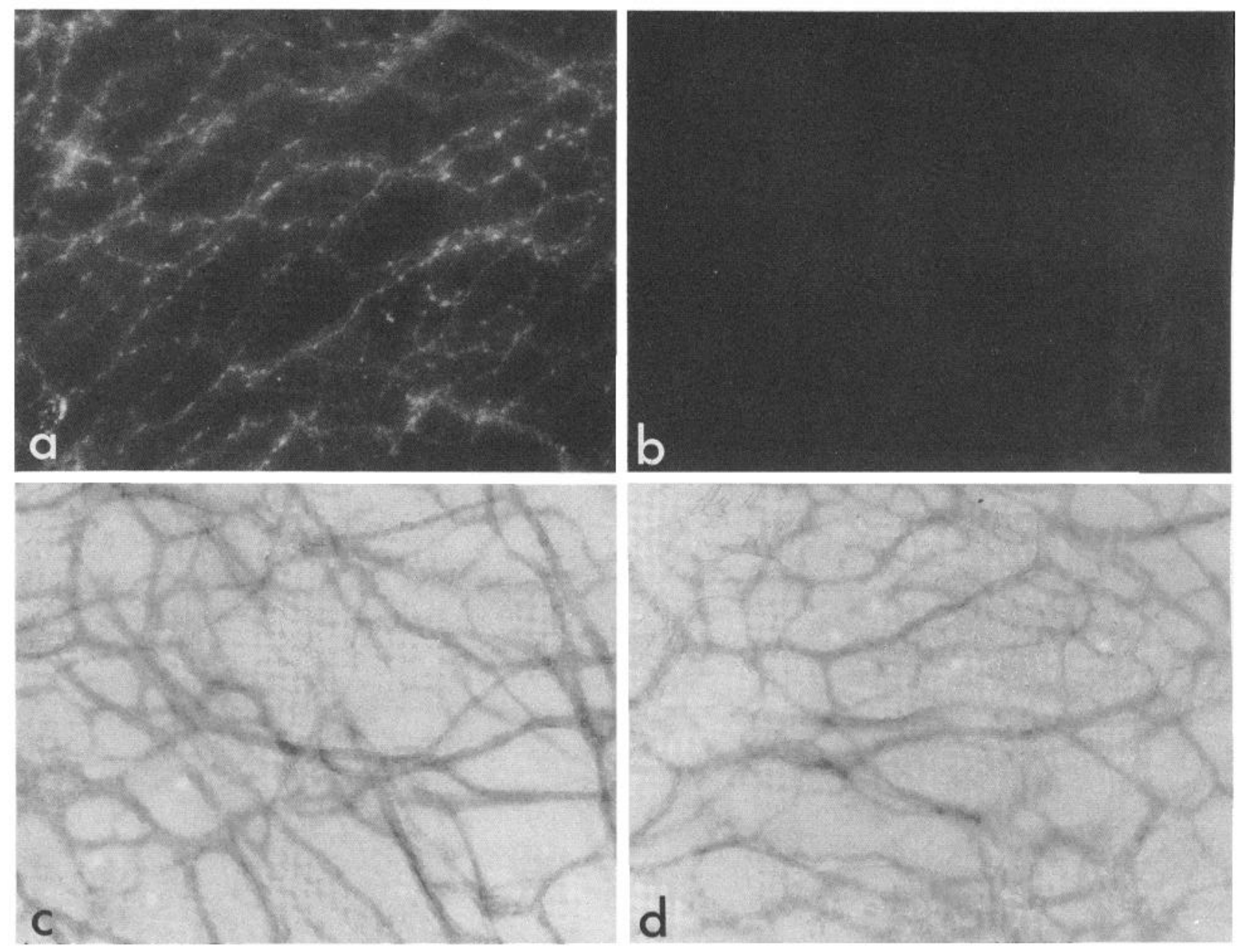

Figure 1. Effect of neonatal 6-OHDA treatment on innervation of the iris. $a$, Fluorescent fibers in the dilator region of an iris stretch preparation, treated with paraformaldehyde vapor, indicate the presence of catecholamines. This is a 4-week-old control rat. Magnification $\times 320$. $b$, No catecholamine-fluorescent fibers are evident in the iris of a 4-week-old rat treated with 6-OHDA as a neonate. Magnification $\times 320 . c, \mathrm{AChE}$ staining discloses a plexus of fibers in the dilator region of an iris stretch preparation in a 4-week-old control rat. Magnification $\times 320$. $d, 6$-OHDA treatment does not affect the AChE staining pattern in the iris in a 4-week-old rat treated as a neonate with 6 -OHDA. Magnification $\times 320$. 

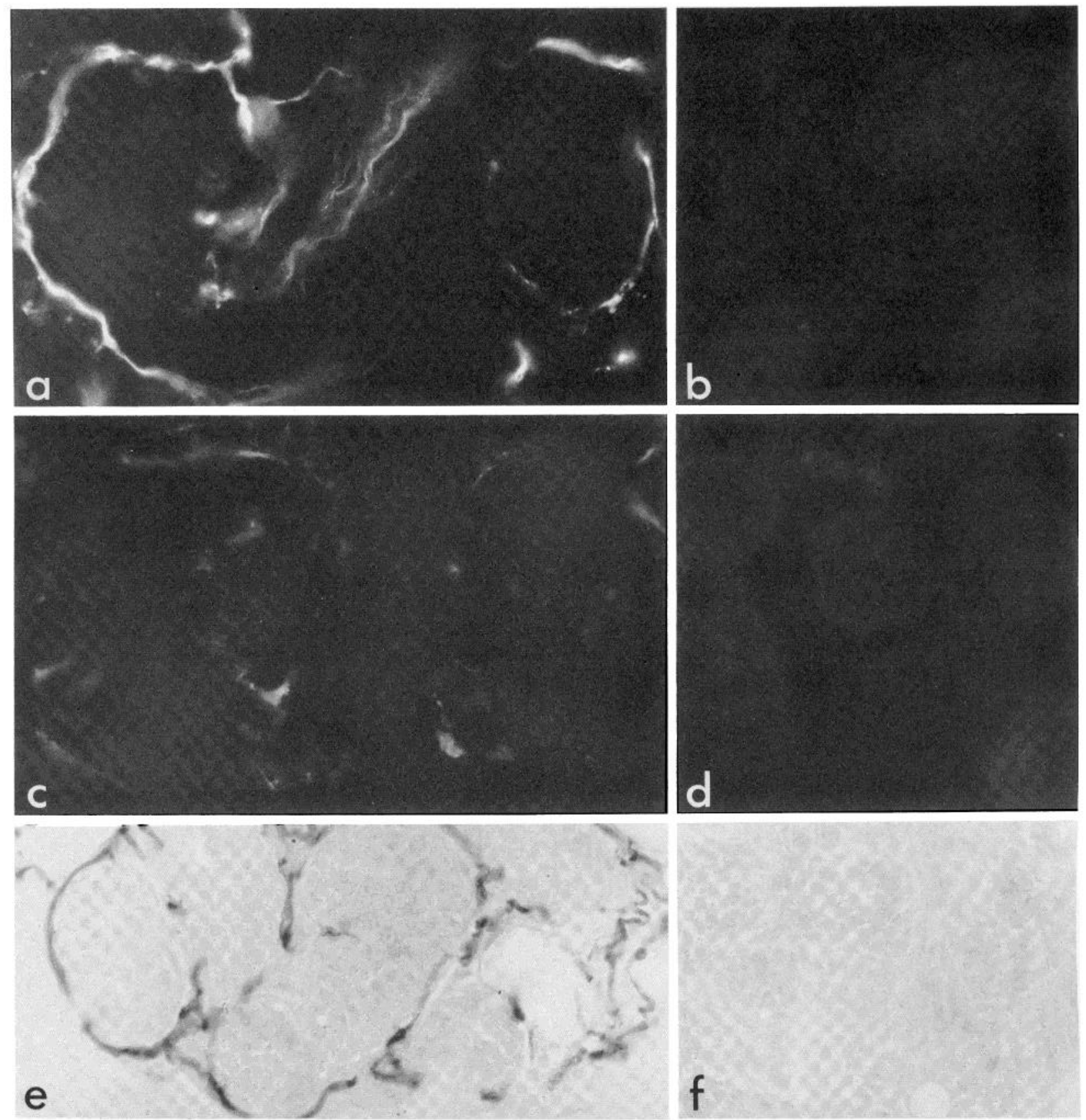

d
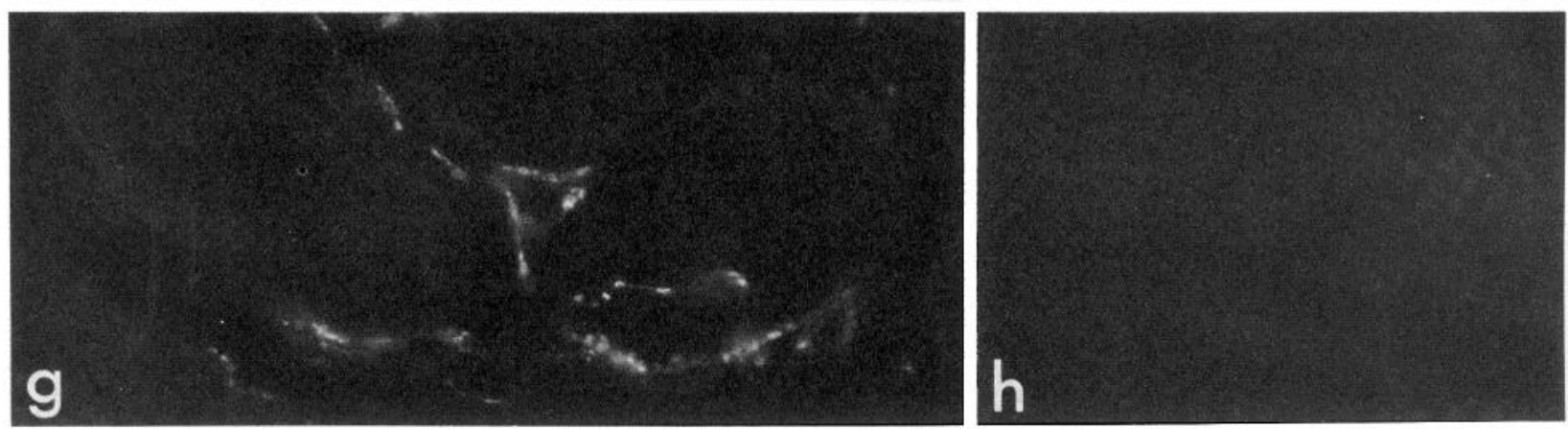

Figure 2. Effect of neonatal 6-OHDA treatment on sympathetic innervation of sweat glands. $a$ and $c$, at $7(a)$ and $14(c)$ days, TH-IR fibers are associated with the developing sweat glands of control rats. Magnification $\times 320 . b$ and $d$, No TH-IR is associated with the developing sweat glands of rat pups treated with 6-OHDA. $b, 7$ days; $d, 14$ days. Magnification $\times 320 . e$, AChE staining reveals a plexus of densely stained fibers in the sweat glands of normal 2-month-old rat. Magnification $\times 320$. $f$, No AChE staining is evident in the sweat glands of a 2-month-old rat treated as a neonate with 6-OHDA. The cells of the secretory tubule appear faintly stained by methylene blue in $e$ and $f$. Magnification $\times 320$. $g$. The axonal plexus in the sweat glands of a normal 2-month-old rat contains VIP-IR. Magnification $\times 320 . h$, No VIP-IR is evident in the sweat glands of a 2 month-old rat treated as a neonate with 6-OHDA. 
to 15 axons arc observed coursing through the secretory portion. In any single section, profiles of both axonal varicosities, which contain numerous clear synaptic vesicles and occasional large dense-core vesicles, and intervaricose regions, which are characterized by the presence of microtubules, can be seen (Fig. $3 a$ ). When the sweat glands of the 6-OHDA-treated animals were examined ultrastructurally, we found that some areas, which in normal animals would typically have contained an axon bundle, were frequently vacant in 6-OHDA-treated animals. However, the sweat glands were not completely devoid of innervation. Some bundles of axons were present, but the axons were morphologically different from those present in the glands of control animals (Fig. 3). Fewer axons were present in each bundle, and the axons contained relatively few microtubules and lacked large, synaptic vesicle-filled varicosities. Some small varicosities were seen, but these contained almost exclusively large dense-core vesicles that appeared larger than those present in the normal cholinergic sympathetic innervation. Despite the abnormal innervation, the secretory tubules of treated animals appeared similar to those of control animals except that the coils of the tubule were packed more tightly in experimental animals than in controls (Fig. 4). Similar findings were observed at periods from 2 weeks to 5 months after the cessation of 6 OHDA treatment.

Several experiments were performed to determine the source of the axons in the sweat glands of the 6-OHDAtreated animals. Sensory fibers are present in the dermis and subcutaneous tissue of the skin and might grow into the denervated glands. Since some of the sensory axons in the skin contain SP (Hökfelt et al., 1975, 1977; Polak and Bloom, 1981; Holzer et al., 1982) and somatostatin, we stained multiple sections of footpads from 10 control and 10 6-OHDA-treated animals for these neuropeptides. Somatostatin-IR fibers were rarely observed in the dermis and were never seen in the sweat glands of normal or 6-OHDA-treated rats. In normal rats, individual SPIR axons were consistently found in every section of the dermis examined but were rarely observed in the sweat glands (Fig. 5a); on average, 1 gland in 20 sampled contained a SP-IR fiber. In contrast, SP-IR fibers were observed in virtually all of the sweat glands of all of the animals treated with 6-OHDA as neonates and examined as adults for SP-IR (Fig. $5 b$ ). Such fibers were associated with the sweat glands of the 6-OHDA-treated animals at 7 days, the earliest time examined. In addition to the appearance of SP-IR fibers in the sweat glands, there was an increase in the number of SP-IR fibers in the dermis of the 6-OHDA-treated animals at all ages examined. To determine whether the axons present in the sweat glands of the 6-OHDA-treated animals were sensory in origin, the fourth, fifth, and sixth lumbar dorsal root ganglia (L4, 5, and $6 \mathrm{DRG}$ ) were removed unilaterally from three treated animals. After 2 days, a decrease was evident in the number of SP-IR fibers in the glands and dermis, and degenerating fibers were present in the sweat glands on the operated side (Fig. $5 d$ ). At 5 days, SP-IR was no longer detectable in the sweat glands, and virtually no axons were identifiable in thin sections of the glands (Fig. 5, $c$ and $e$ ). Thus, sensory axons grew into the swcat glands which had been denervated by the 6-OHDA treatment of neonatal animals.

The distributions of sympathetic and sensory fibers overlap in targets other than the skin, and it was of interest to determine whether chemical sympathectomy would influence sensory fibers elsewhere. One such shared target is the iris, which receives a SP-IR projection from the Gasserian ganglion (Fig. 6a) (Hökfelt et al., 1977; Butler et al., 1980; Miller et al., 1981; Tervo et al., 1981; Polak and Bloom, 1981; Kessler et al., 1983a; Tornqvist et al., 1982). There was approximately a 2fold increase in the number of SP-IR fibers in the irides of animals treated with 6-OHDA as neonates (Fig. 6b). No obvious change in the density of SP-IR fibers associated with blood vessels in the footpads or tongue, which are normally sparsely innervated by SP-IR fibers (Hökfelt et al., 1977; Cuello et al., 1978; Polak and Bloom, 1981; Furness et al., 1982), was observed.

Chemical sympathectomy can also be achieved in neonatal rats by chronic treatment with guanethidine (Eränkö and Eränkö, 1971; Herskovits and Singh, 1982; Manning et al., 1983). When pups which had been treated with guanethidine were examined at 8 weeks, the changes in the sweat gland innervation appeared similar but not completely identical to those observed after 6-OHDA treatment. No AChE (Fig. 7a) or VIP-IR was evident in the sweat glands (Fig. 7b). As in the 6-OHDA-treated animals, SP-IR fibers and bundles of axons which lacked varicosities were present in the glands (Fig. 7c). However, the SP-IR innervation did not appear as dense in the guanethidine-treated animals as in the 6-OHDA-treated rats. In contrast, the axon bundles appeared to contain more axons than in the 6-OHDA-treated animals.

Treatment of adult rats. The effects of 6-OHDA treatment of adult rats were evaluated 2 weeks after the initial injection (Fig. 8). As in the neonatally treated animals, there was a loss of catecholamine-containing fibers in the iris and submandibular salivary gland, and the AChE staining in the iris and salivary gland was not affected. In contrast to the neonatally treated animals, the AChE staining and VIP-IR in the sweat glands of the animals treated as adults appeared identical in distribution and extent to those observed in control animals. Ultrastructural examination of the sweat gland innervation of the animals treated with 6-OHDA as adults disclosed no obvious toxic effects of the injections. The axon bundles appeared normal in their distribution, and the ultrastructural appearance of the axons was similar to those of control animals (Fig. 9a). Occasional axons showed evidence of minor damage: they contained autophagic vacuoles, unusual vesicle profiles, or unusually dense axoplasm (Fig. 9a). Noradrenergic fibers associated with blood vessels in the footpads were destroyed after both neonatal and adult 6-OHDA treatments. Thus, it seems very unlikely that the difference observed in the responsiveness of the immature and mature cholinergic sympathetic fibers was due to altered distribution of the injected drug at the different ages. When adult rats were treated with higher doses of $6-O H D A(200 \mathrm{mg} / \mathrm{kg}$; two times/day), degenerating axon and terminal profiles were frequently seen in the sweat gland innervation after the third injection (Fig. $8 b$ ). After 7 days of treatment, the 

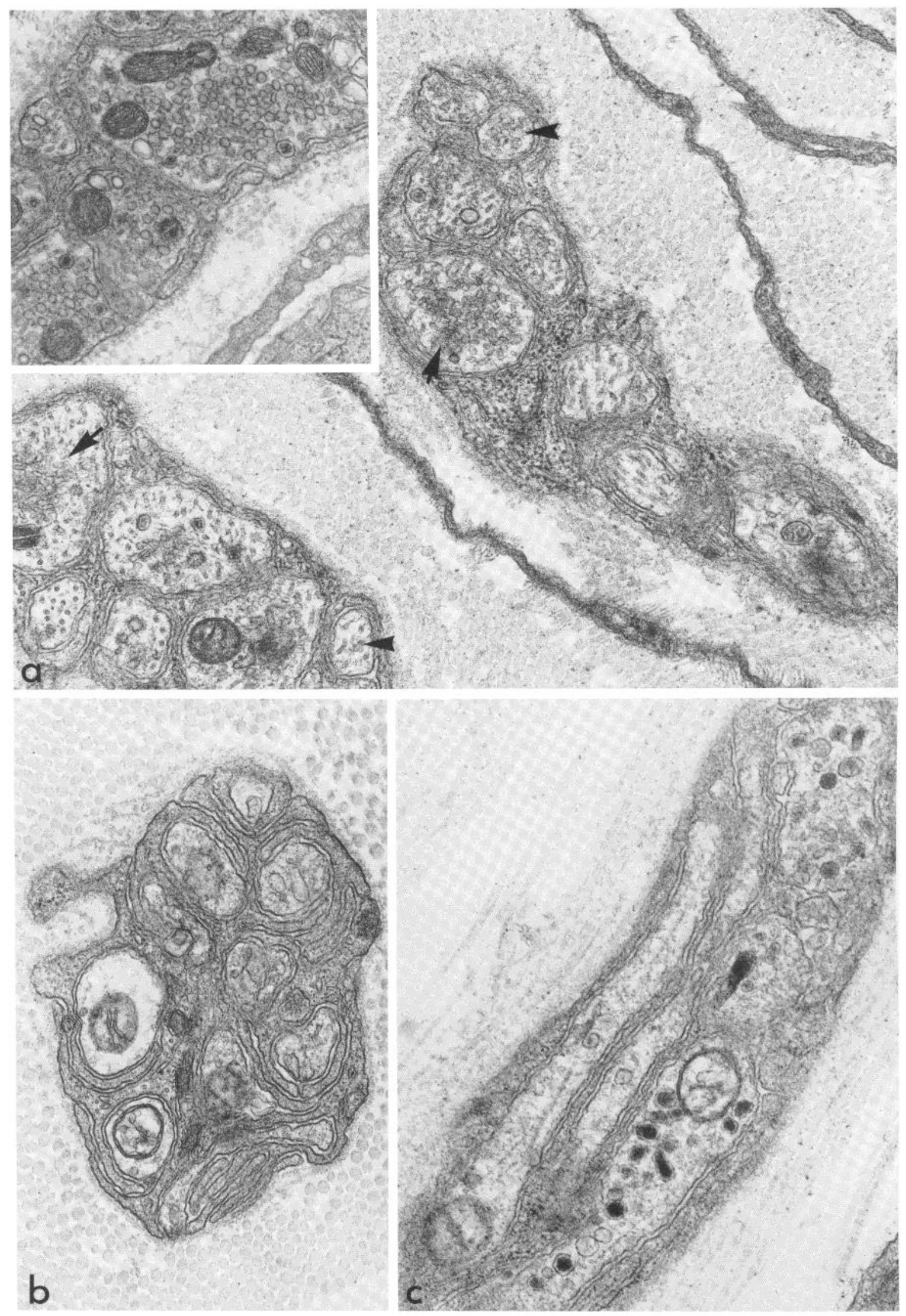

Figure 3. Innervation of sweat glands in normal and experimental animals. $a$, In normal animals, intervaricose axonal segments in the sweat glands (arrowheads) have lucent axoplasm and numerous microtubules. Two axon profiles (arrows) have been sectioned close to varicosities; small clusters of vesicles that appear flattened because of primary fixation with $4 \%$ paraformaldehyde are evident. The axonal mitochondria have a characteristic dense matrix. Several varicosities are evident in the inset. Magnification $\times 31,000 . b$ and $c$, The sweat glands of rats treated as neonates with 6-OHDA contain few microtubules, and they lack large synaptic vesicle-filled varicosities. Small varicosities with large dense-core vesicles are present. The cores present in the vesicles vary in electron density. Paraformaldehyde fixation. Magnification $\times 31,000$. 

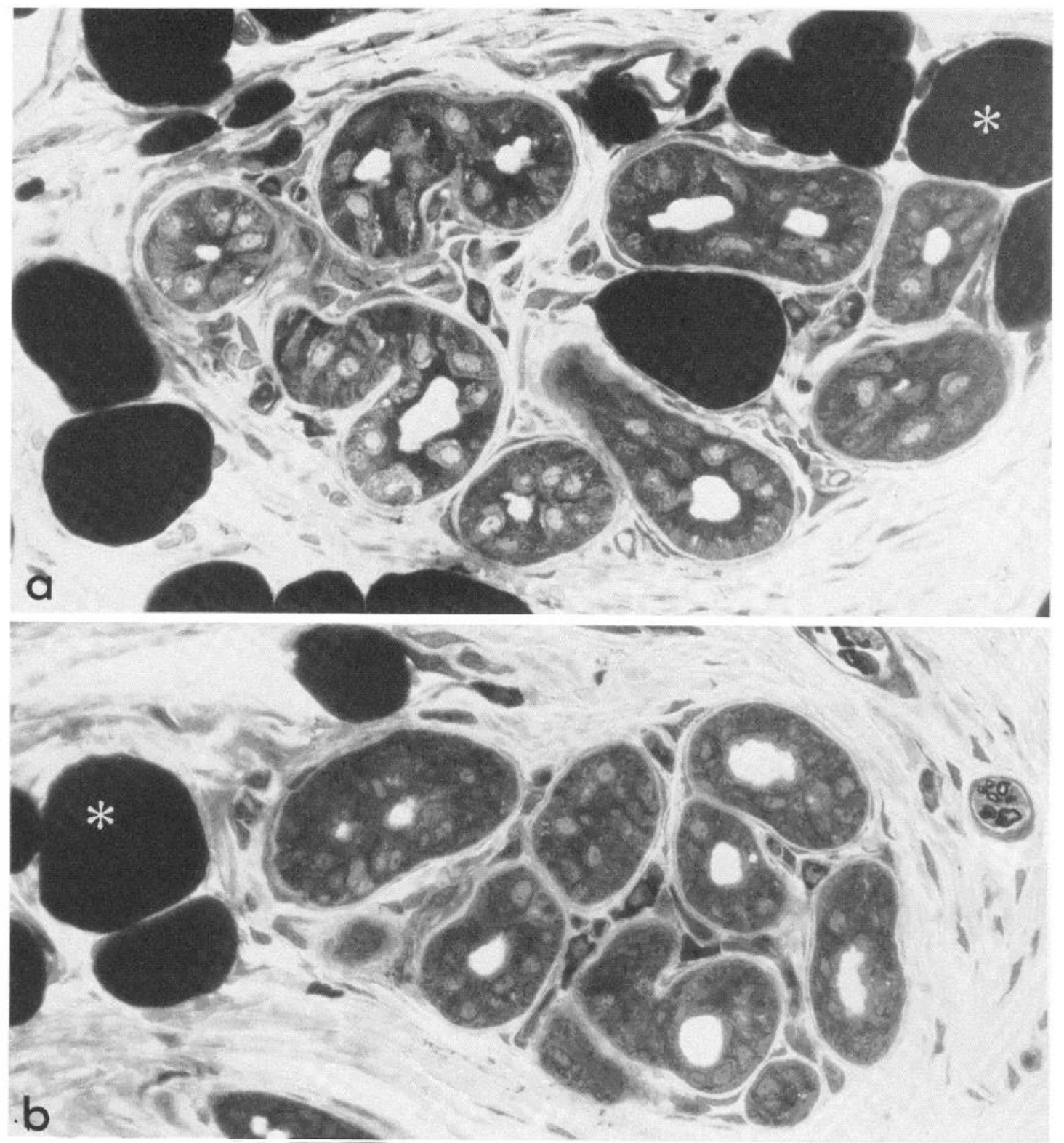

Figure 4. Effects of neonatal treatment with 6-OHDA on sweat gland morphology. The tubule profiles of the sweat glands in normal animals $(a)$ are separated from each other by connective tissue elements. After 6-OHDA treatment, the coils of the secretory tubule appear more closely packed $(b)$. Asterisk, fat cell. These are $1-\mu \mathrm{m}$ plastic sections stained with toluidine blue. Magnification $\times 425$.

number of axons in the bundles was reduced to approximately half, and some remaining profiles looked abnormal. In contrast, parasympathetic cholinergic terminals in the irides of previously sympathectomized rats appeared unaffected by 6-OHDA treatment, even with this high dose.

\section{Discussion}

The dopamine congener, 6-OHDA, causes the selective destruction of noradrenergic terminals in the peripheral nervous system of adult animals (Tranzer and Thoenen, 1968; Knyihar et al., 1969; De Champlain, 1971; Lorez et al., 1975). Since the neuron cell bodies are not affected, the axon terminals regenerate with time (Malmfors and Sachs, 1968; Jonsson and Sachs, 1972; Lorez et al., 1975). Toxicity requires uptake via the high affinity catechol- amine uptake system into the terminal (Malmfors and Sachs, 1968; Bennett et al., 1970) where toxic intermediates are formed (Saner and Thoenen, 1971; Heikkila and Cohen, 1973; Tiffany-Castiglioni et al., 1982). As previously reported by others, we have found that treatment of adult animals with 6-OHDA $(100 \mathrm{mg} / \mathrm{kg}$ on days 1 to 7 and day 12) resulted in the disappearance of catecholaminergic fibers from the iris, salivary glands, and blood vessels of the footpads. 6-OHDA treatment did not cause the degeneration of AChE-positive (putatively cholinergic parasympathetic) terminals in the iris or salivary glands or of cholinergic sympathetic fibers in the sweat glands of adult rats. In the sweat glands, $\mathrm{AChE}$ staining and VIP-IR appeared unchanged, and only minor ultrastructural changes were evident. Resistance to 6-OHDA has also been reported for sweat gland inner- 

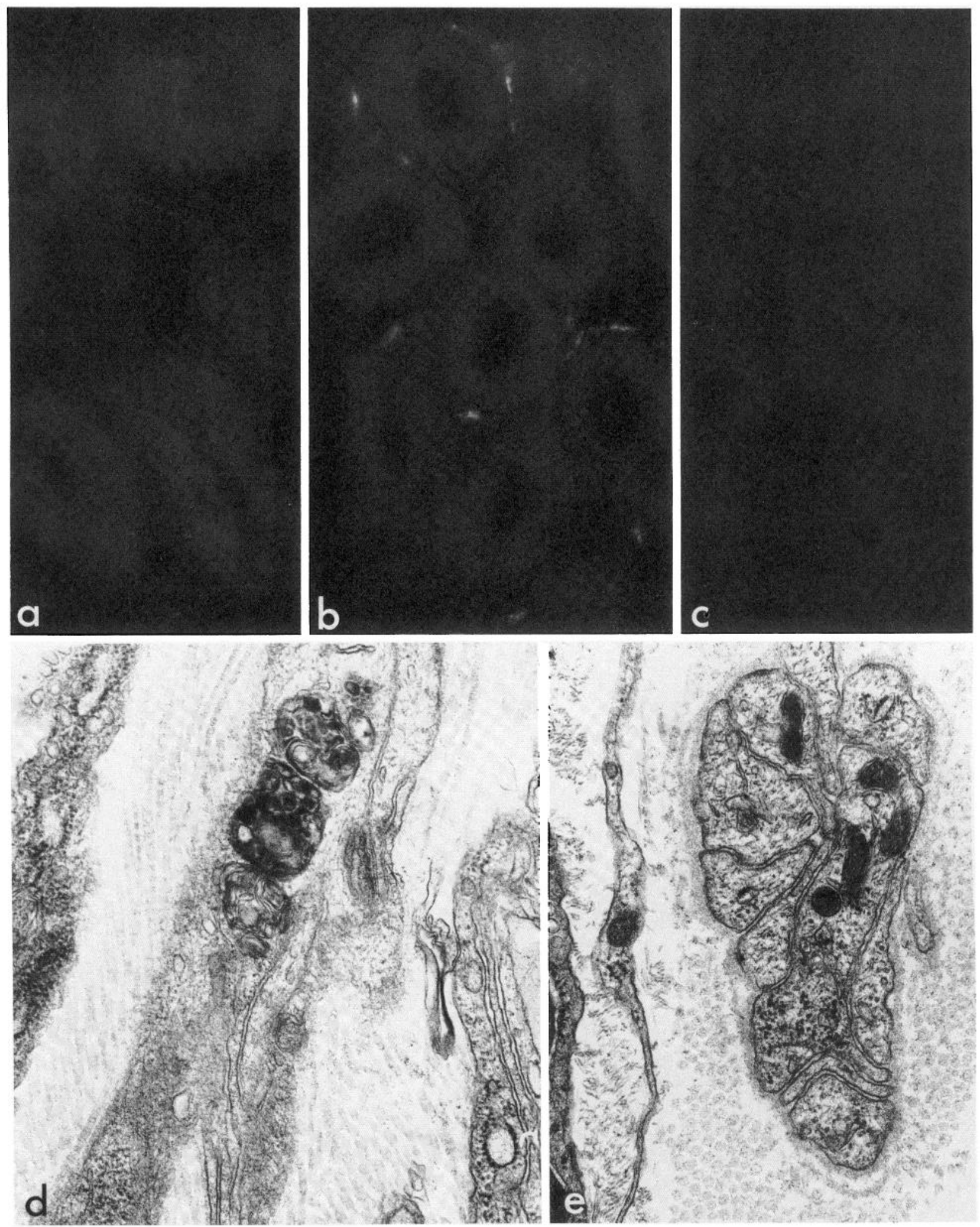

Figure 5. Sensory innervation of sweat glands of rats treated with 6-OHDA. $a$, No SP-IR is present in most sweat glands of normal rats. This is a 6-week-old rat. Magnification $\times 320 . b$, SP-IR fibers are present in sweat glands of rats treated as neonates with 6-OHDA. The SP-IR fibers appear thinner than those of the normal innervation seen with VIP-IR or AChE staining. This is a 6 -week-old rat. Magnification $\times 320$. $c$, SP-IR fibers disappear after removal of L4, 5, and 6 dorsal root ganglia. This is a 9week-old rat, 5 days after sensory ganglionectomy. Magnification $\times 320$. $d, 2$ days after removal of L4, 5 , and 6 dorsal root ganglia, degenerating terminals are evident in the axon bundles in the sweat glands. Magnification $\times 31,000$. $e, 5$ days after removal of L4, 5 , and 6 dorsal root ganglia, only Schwann cell processes, identified by the presence of polysomes and prominent intermediate filaments, are present in most nerve fibers. Magnification $\times 31,000$. 

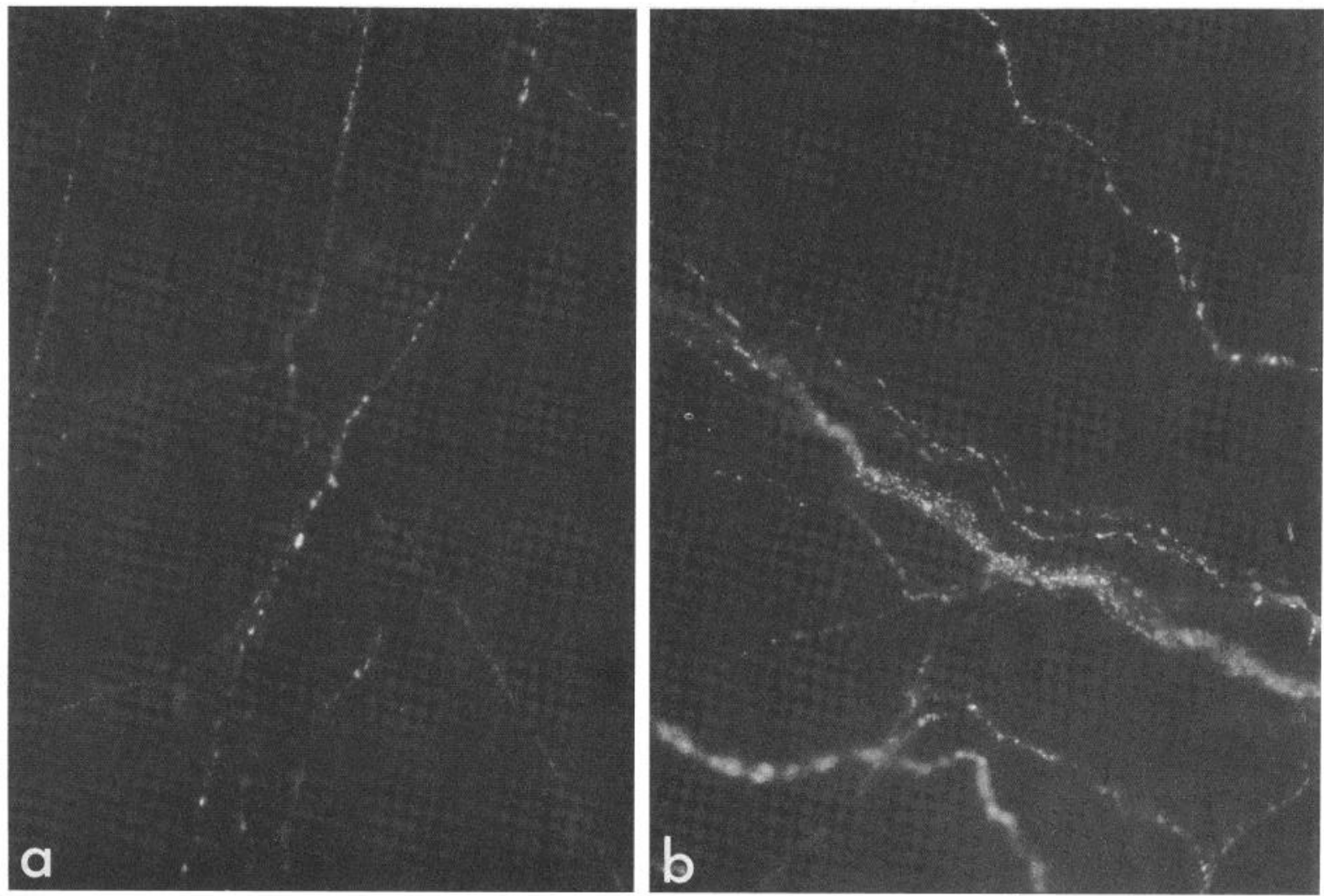

Figure 6. SP-IR in iris of normal and 6-OHDA-treated rats. $a$, A sparse SP-IR plexus is evident in the irides of normal rats. Magnification $\times 320$. $b$, In rats treated with $6-\mathrm{OHDA}$ as neonates, there is a 2 -fold increase in the number of SP-IR fibers compared to control animals. Magnification $\times 320$.
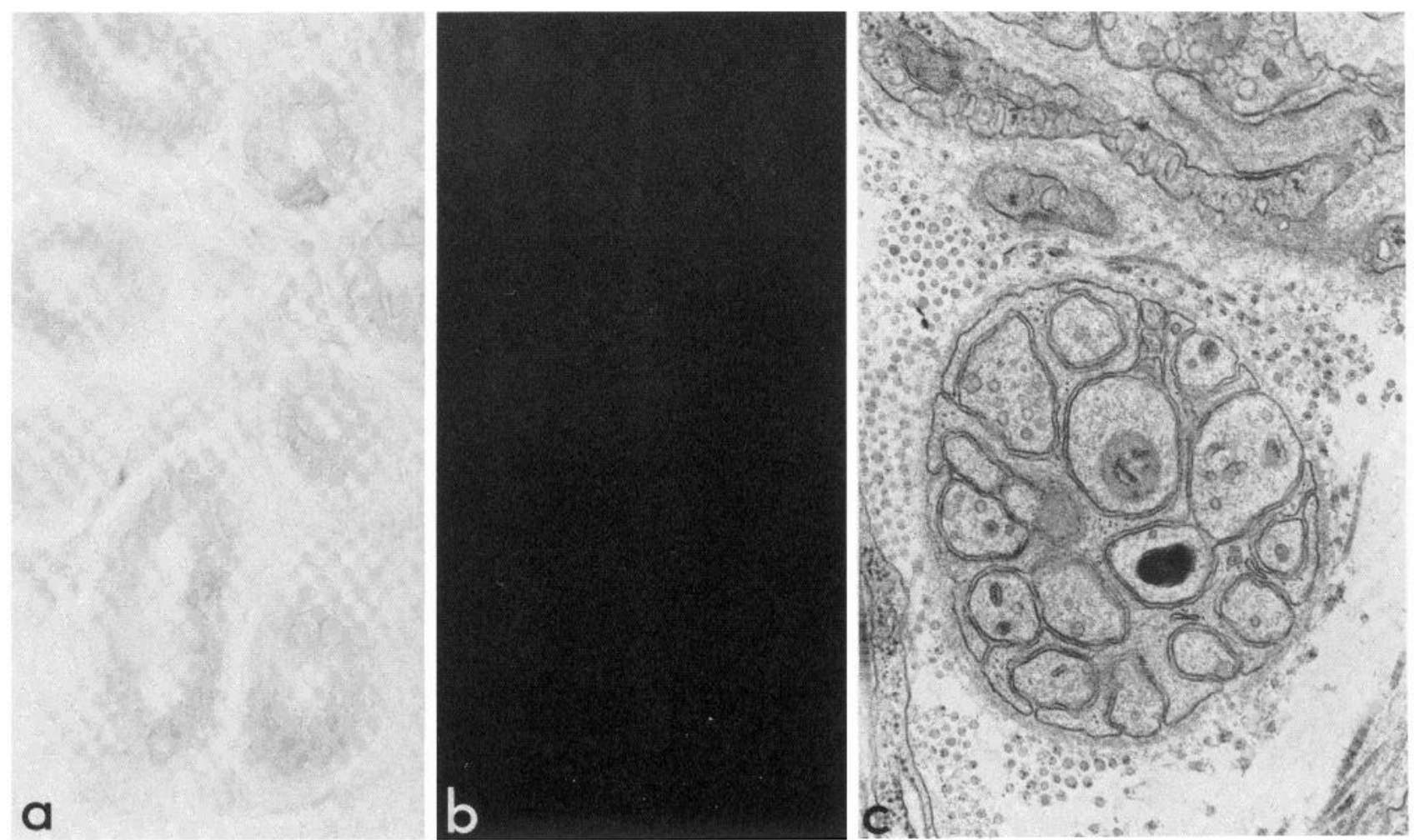

Figure 7. Effects of neonatal treatment with guanethidine on sweat gland innervation. No AChE $(a)$ staining or VIP-IR $(b)$ is evident in the sweat glands of rats treated as neonates with guanethidine. However, bundles of axons are seen in thin section. These axons do not display typical sympathetic varicosities but resemble those seen in the 6-OHDA-treated rats. Magnifications: $a$ and $b, \times 320 ; c, \times 31,000$. 

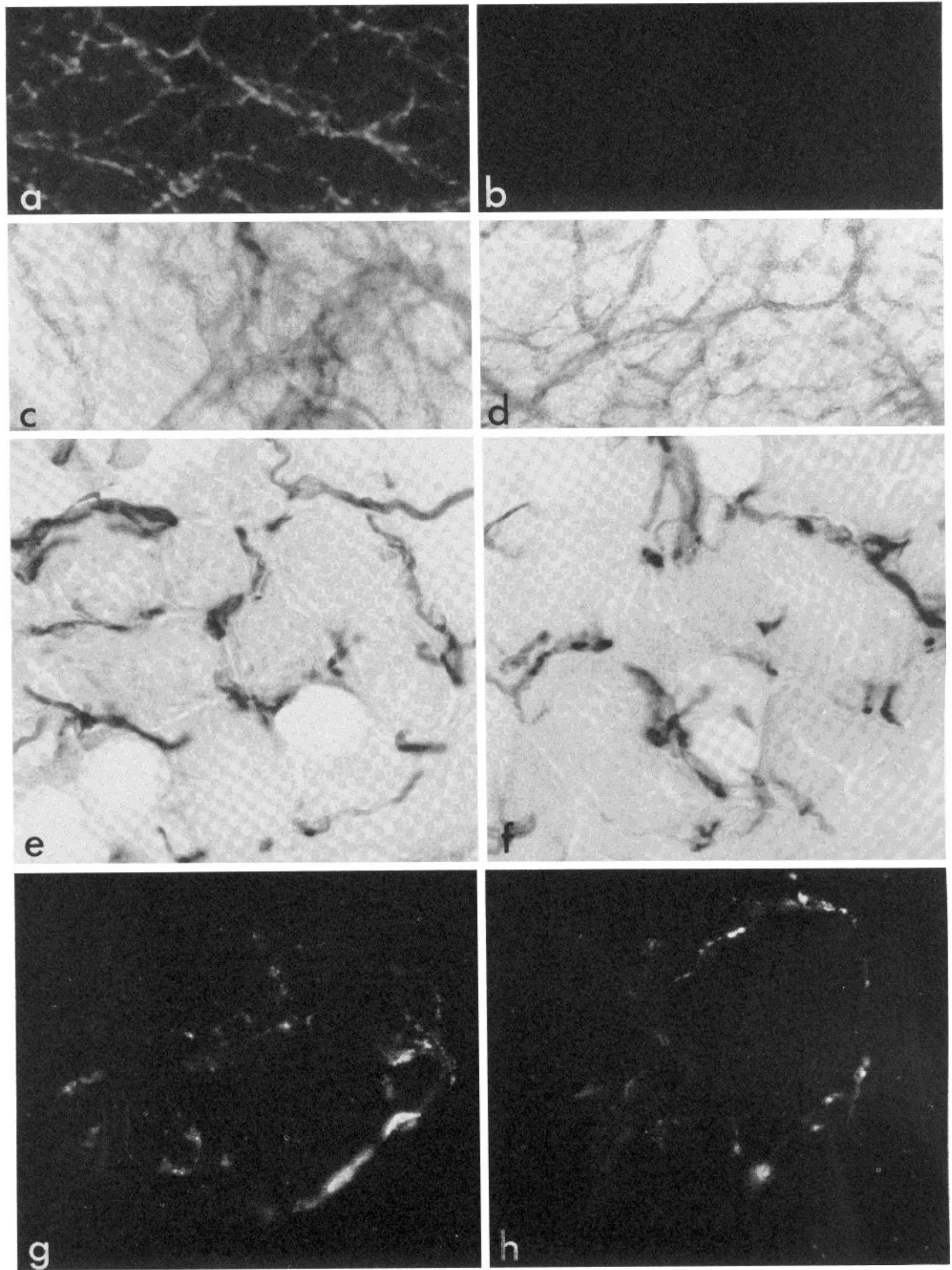

Figure 8. Effects of 6-OHDA treatment of adult rats on sympathetic innervation of iris and sweat glands. $a$ and $b, 6$-OHDA treatment of adult animals eliminates the formaldehyde-induced catecholamine fluorescent plexus $(b)$ present in the iris of normal animals $(a)$ Magnification $\times 320$. $c$ and $d, 6$-OHDA treatment of adult rats does not affect AChE staining in the iris. $c$, control; $d, 6$-OHDA-treated rat. Magnification $\times 320$. $e$ to $h, 6$-OHDA treatment of adult rats does not affect AChE $(e$ and $f)$ or VIP-IR $(g$ and $h$ ) staining in sweat glands. $e$ and $g$, control; $f$ and $h, 6$-OHDA-treated rat. Magnification $\times 320$. 

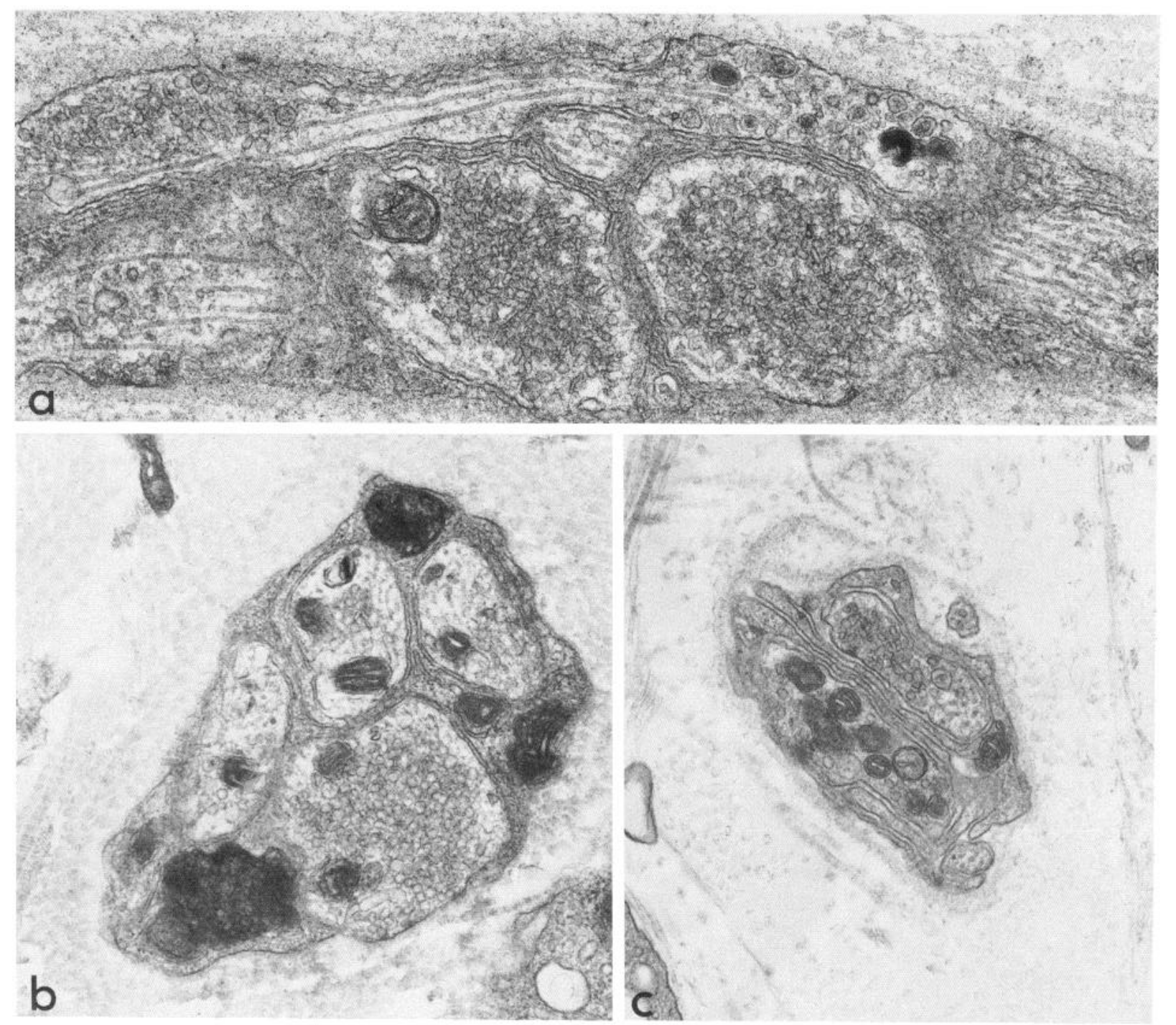

Figure 9. Effects of 6-OHDA treatment of adult rats on cholinergic sympathetic innervation of sweat glands. $a$ to $c$, The axon terminals appear normal after treatment with $6-$ OHDA with a protocol identical to that used to treat neonatal rats $(100 \mathrm{mg} / \mathrm{kg}$ daily for 7 days). Paraformaldehyde fixation. Magnification $\times 31,000$. $b$, Degenerating terminals are evident in the sweat gland innervation during the course of treatment with higher doses of $6-$ OHDA $(200 \mathrm{mg} / \mathrm{kg}$ twice daily). Magnification $\times 31,000$. $c$, Following 1 week of 6-OHDA treatment with higher doses of 6 -OHDA ( $200 \mathrm{mg} / \mathrm{kg}$ twice daily), the number of axons in each bundle is reduced to approximately half. Schwann cell processes made redundant by axonal loss are observed folding back on each other. Magnification $\times 31,000$.

vation in primates by Uno and Montagna (1975). Although sympathetic terminals in the sweat glands of adult rats can take up and store exogenous catecholamine (Landis and Keefe, 1983), the accumulation by cholinergic sympathetic terminals was less than that observed in noradrenergic sympathetic fibers. Since the destruction of catecholaminergic terminals by 6 -OHDA is dosedependent (Thoenen and Tranzer, 1968; Malmfors and Sachs, 1968; Bennett et al., 1970), it seems likely that at the dose used the sweat gland terminals did not accumulate enough 6-OHDA to cause degeneration. Indeed, we found that if rats were treated with a higher dose ( 200 $\mathrm{mg} / \mathrm{kg}$, two times/day) significant numbers of degenerating terminals were observed in the sweat glands. We do not know whether all sweat gland fibers can be eliminated by increasing the dose further because higher doses $(300 \mathrm{mg} / \mathrm{kg}, 1$ or 2 days) proved lethal.
Treatment of neonatal animals with 6-OHDA causes the destruction of the entire peripheral noradrenergic neuron (Angeletti and Levi-Montalcini, 1970; Angeletti, 1971; Jaim-Etcheverry and Zieher, 1971; Clark et al., 1972; Finch et al., 1973). The difference in the effect of 6-OHDA on adult and neonatal sympathetic neurons has been attributed to a greater requirement of immature than mature sympathetic neurons for NGF (Thoenen and Barde, 1980; Levi-Montalcini, 1982). Destruction of the axon terminals in neonatal animals by 6-OHDA would result in the loss of retrogradely transported NGF, which is essential for survival (Hendry, 1975; Levi-Montalcini et al., 1975; Aloe et al., 1975; Johnson et al., 1979). In contrast to the relative lack of effect of 6-OHDA on mature sweat gland innervation, we have found that neonatal treatment with 6-OHDA eliminates the developing sweat gland innervation and, therefore, results in 
the absence of sympathetic terminals from the mature glands. Catecholamine histofluorescence and TH-IR were missing from the developing glands, and $\mathrm{AChE}$ staining, VIP-IR, and morphologically characteristic axonal varicosities were missing from the mature sweat glands. The parasympathetic innervation of the iris and submandibular gland assayed by AChE staining was unaffected by neonatal 6-OHDA treatment.

The effective destruction of the developing sweat gland innervation was not restricted to a single adrenergic neurotoxin, 6-OHDA. In rats, chronic treatment of neonatal or adult animals with guanethidine has been shown previously to cause the destruction of peripheral noradrenergic sympathetic neurons (Eränkö and Eränkö, 1971; Burnstock et al., 1971; Johnson and O'Brien, 1976; Heath and Burnstock, 1977; Herskovits and Singh, 1982). Like 6-OHDA, guanethidine is accumulated in noradrenergic neurons via the high affinity uptake system (Mitchell and Oates, 1970). However, in contrast to 6-OHDA, the guanethidine-induced destruction appears to be mediated by the immune system (Manning et al., 1982, 1983). We found that chronic treatment of neonatal rats with guanethidine replicated the effects of neonatal 6-OHDA treatment on the developing sweat gland innervation. AChE, VIP-IR, and typical sympathetic axonal varicosities were absent, while SP-IR and sensory terminals were present in the treated animals.

During development, the axons which initially become associated with the sweat glands exhibit prominent catecholaminergic properties during the second postnatal week. They possess TH-IR (Siegel et al., 1982), formaldehyde-induced catecholamine histofluorescence, and SGV after permanganate fixation (Landis and Keefe, 1983). AChE and VIP-IR appear at 10 days (Siegel et al., 1982). Then, as the axons form an extensive plexus and the glands mature, the noradrenergic properties decrease and AChE and VIP-IR increase (Siegel et al., 1982; Landis and Keefe, 1983). Initially, all of the sweat gland axons contain SGV, but during the transitional period, the proportion of SGV in the terminals decreases while degenerating terminals are never seen. The ultrastructural observations suggest that the changes in neurotransmitter-related properties observed with the light microscope occur in a single population of axons and, therefore, that the early noradrenergic innervation gives rise to the mature, functionally cholinergic innervation.

The absence of cholinergic sympathetic innervation in adult rats following neonatal 6-OHDA and guanethidine treatment provides further evidence for neurotransmitter plasticity in the sweat gland axons. An alternative explanation for our observations is that the noradrenergic fibers serve as pioneer fibers (e.g., Bentley and Keshishian, 1982; Ho and Goodman, 1982) and their elimination prevents the ingrowth of later arriving cholinergic axons. We cannot exclude this possibility at the present time, but it is clear that sensory fibers, present in the local environment, at least can grow into and innervate the glands of the 6-OHDA-treated animals. A similar functional transition involving the loss of noradrenergic properties may occur during neuronal development in the embryonic rodent gut. On embryonic day 11, a population of TH-IR and catecholamine histofluorescent cells appears (Cochard et al., 1979; Teitelman et al.,
1979), but by embryonic day 14 the TH-IR and catecholamine fluorescence have disappeared. Several lines of evidence suggest that the transient catecholaminergic cells have not died but rather changed their properties (Jonakait et al., 1979, 1981; Kessler et al., 1979). Although the evidence is consistent with transmitter plasticity in this system, it has been difficult to establish the final phenotype of these cells and thereby a transitional state.

The sympathetically denervated sweat glands of rats treated as neonates with 6-OHDA do not remain uninnervated. Some of the axons that grow in are immunoreactive for SP and are presumably sensory in origin since they degenerate following removal of lumbar sensory ganglia. The axon terminals appear morphologically different from those normally present in the glands since they contain almost no small synaptic vesicles and only small numbers of large dense-core vesicles. It is of interest that these terminals are also morphologically different from the central terminals of SP-containing neurons that contain numerous synaptic vesicles (Barber et al., 1979; De Figlia et al., 1982). In contrast to sweat glands in cat, which do contain SP-IR fibers (Hökfelt et al., 1975, 1977; Polak and Bloom, 1981), the sweat glands of rats do not normally contain SP-IR fibers, and we do not know if these endings play any functional role in the 6-OIIDA-treated animals. The glands develop relatively normally by morphological criteria when innervated by sensory, rather than sympathetic, axons. This observation suggests that either the glands do not require trophic interactions with neurons or that the sensory axons can substitute for sympathetic. Despite their ingrowth into the sweat glands, the sensory axons, in contrast to the cholinergic sympathetic axons, do not acquire AChE activity.

The response of sensory afferents to sympathetic denervation is not restricted to sweat glands. An increase in sensory SP-IR has been detected with radioimmunoassay (RIA) in irides of rats treated with 6-OHDA as neonates (Kessler et al., 1983a, b). We have also observed a significant increase in the number of SP-IR fibers in the irides of rats treated with 6-OHDA as neonates. This suggests that the increase in SP levels observed with RIA is the result of sprouting in the sensory plexus of the iris. However, we cannot exclude the possibility that the apparent increase in the density of SP-IR fibers was due to increases in SP-IR in axons already present but not previously detected with our immunocytochemical assay. The SP-IR sensory plexus did not increase in all of the sympathetically denervated targets. No obvious increase in the number of SP-IR fibers along blood vessels was seen in the present study or in the pineal in a previous study (Kessler et al., 1983a, b).

NGF is a likely candidate to mediate the response of sensory afferents to sympathetic denervation. NGF has been shown to affect both sympathetic and sensory neurons with respect to directing axonal growth (Campenot, 1977; Menesini Chen et al., 1978; Letourneau, 1978; Gundersen and Barrett, 1979) and trophic regulation of neurotransmitter and peptide levels (Gorin and Johnson, 1980; E. Johnson et al., 1980; Kessler and Black, 1980, 1981; Thoenen and Barde, 1980; Goedert et al., 1981; Ross et al., 1981; Levi-Montalcini, 1982). Both sensory 
and sympathetic denervation of the iris have been shown to result in the appearance of NGF-like activity (Ebendal et al., 1980), and injection of anti-NGF has been shown to block the increase in SP-IR observed in the iris after sympathetic denervation (Kessler et al., 1983b). Our observations suggest that the sweat glands like the iris produce NGF-like activity upon denervation but that blood vessels may not. It will be of interest to examine the mechanisms that determine the relative contributions of sympathetic and sensory innervation of peripheral targets, such as the sweat gland and iris.

\section{References}

Aloe, L., E. Mugnaini, and R. Levi-Montalcini (1975) Light and electron microscopic studies on the excessive growth of sympathetic ganglia in rats injected daily from birth with 6OHDA and NGF. Arch. Ital. Biol. 113: 326-353.

Angeletti, P. U. (1971) Chemical sympathectomy in newborn animals. Neuropharmacology 10: 55-59.

Angeletti, P. U., and R. Levi-Montalcini (1970) Sympathetic nerve cell destruction in newborn mammals by 6 -hydroxydopamine. Proc. Natl. Acad. Sci. U. S. A. 65: 114-121.

Barber, R. P., J. E. Vaughn, J. R. Slemmon, P. M. Salvaterra, E. Roberts, and S. E. Leeman (1979) The origin, distribution and synaptic relationships of substance $P$ axons in rat spinal cord. J. Comp. Neurol. 184: 331-352.

Bennett, T., G. Burnstock, J. L. S. Cobb, and T. Malmfors (1970) An ultrastructural and histochemical study of the short-term effects of 6-hydroxydopamine on adrenergic nerves in the domestic fowl. Br. J. Pharmacol. 38: 802-809.

Bentley, D., and H. Keshishian (1982) Pathfinding by peripheral pioneer neurons in grasshoppers. Science 218: 10821088.

Burnstock, G., B. Evans, B. J. Gannon, J. W. Heath, and V. James (1971) A new method of destroying adrenergic nerves in adult animals using guanethidine. Br. J. Pharmacol. 43: 295-301.

Butler, J. M., D. Powell, and W. G. Unger (1980) Substance P levels in normal and sensorily denervated rabbit eyes. Exp. Eye Res. 30: 311-313.

Campenot, R. B. (1977) Local control of neurite development by nerve growth factor. Proc. Natl. Acad. Sci. U. S. A. 74: 4516-4519.

Clark, D. W. J., R. Laverty, and E. L. Phelan (1972) Longlasting peripheral and central effects of 6 -hydroxydopamine in rats. Br. J. Pharmacol. 44: 233-243.

Cochard, P., M. Goldstein, and I. B. Black (1979) Initial development of the noradrenergic phenotype in autonomic neuroblasts of the rat embryo in vivo. Dev. Biol. 71: 100-114.

Cuello, A. C., M. Del Fiacco, and G. Paxinos (1978) The central and peripheral ends of the substance P-containing neurones in the rat trigeminal system. Brain Res. 152: 499-509.

De Champlain, J. (1971) Degeneration and regrowth of adrenergic nerve fibers in the rat peripheral tissues after 6hydroxydopamine. Can. J. Physiol. Pharmacol. 49: 345-355.

Di Figlia, M., N. Aronin, and S. E. Leeman (1982) Light microscopic and ultrastructural localization of immunoreactive substance $P$ in the dorsal horn of monkey spinal cord. Neuroscience 7: 1127-1139.

Ebendal, T., L. Olson, A. Seiger, and K. -O. Hedlund (1980) Nerve growth factors in the rat iris. Nature 286: 25-28.

Ehinger, B. (1966) Ocular and orbital vegetative nerves. Acta Physiol. Scand. 67 (Suppl. 268): 5-35.

Eränkö, L., and O. Eränkö (1971) Effects of guanethidine on nerve cells and small intensely fluorescent cells in sympathetic ganglia of newborn and adult rats. Acta Pharmacol. Toxicol. 30: 403-416.
Fahrenkrug, J., and O. Shaffahtzky de Muckadell (1977) Radioimmunoassay of vasoactive intestinal (VIP) in plasma. J. Lab. Clin. Med. 89: 1379-1388.

Finch, L., G. Haeusler, and H. Thoenen (1973) A comparison of the effects of chemical sympathectomy by 6-hydroxydopamine in newborn and adult rats. Br. J. Pharmacol. 47: $249-260$.

Freitag, P., and M. B. Engel (1970) Autonomic innervation in rabbit salivary glands. Anat. Rec. 167: 87-106.

Furness, J. B., R. E. Papka, N. G. Della, M. Costa, and R. L. Eskay (1982) Substance P-like immunoreactivity in nerves associated with the vascular system of guinea-pigs. Neuroscience 7: 447-459.

Goedert, M., K. Stoeckel, and U. Otten (1981) Biological importance of the retrograde axonal transport of nerve growth factor in sensory neurons. Proc. Natl. Acad. Sci. U. S. A. 78: 5895-5898.

Gorin, P. D., and E. M. Johnson (1980) Effects of long-term nerve growth factor deprivation on the nervous system of the adult rat: An experimental autoimmune approach. Brain Res. 198: 27-42.

Gundersen, R. W., and J. N. Barrett (1979) Neuronal chemotaxis: Chick dorsal-root axons turn toward high concentrations of nerve growth factor. Science 206: 1079-1080.

Heath, J. W., and G. Burnstock (1977) Selectivity of neuronal degeneration produced by chronic guanethidine treatment. J. Neurocytol. 6: 397-405.

Heikkila, R. E., and G. Cohen (1973) 6-hydroxydopamine: Evidence for superoxide radical as an oxidative intermediate. Science 181: 456 -457 .

Hendry, I. A. (1975) The response of adrenergic neurones to axotomy and nerve growth factor. Brain Res. 94: 87-97.

Herskovits, M. S., and I. J. Singh (1982) Histologic evaluation of the sympathectomy induced by guanethidine sulfate in neonatal rats. J. Exp. Zool. 223: 97-101.

Ho, R. K., and C. S. Goodman (1982) Peripheral pathways are pioneered by an array of central and peripheral neurones in grasshopper embryos. Nature 297: 404-406.

Höfelt, T., J. -O. Kellerth, G. Nilsson, and B. Pernow (1975) Experimental immunohistochemical studies on the localization and distribution of substance $P$ in cat primary sensory neurons. Brain Res. 100; 235-252.

Hökfelt, T., O. Johansson, J. -O. Kellerth, A. Ljungdahl, G. Nilsson, A. Nygårds, and B. Pernow (1977) Immunohistochemical distribution of substance P. In Substance P, U. S. von Euler and B. Pernow, eds., pp. 117-145, Raven Press, New York.

Holzer, P., A. Bucsics, and F. Lembeck (1982) Distribution of capsaicin-sensitive nerve fibres containing immunoreactive substance $P$ in cutaneous and visceral tissues of the rat. Neurosci. Lett. 31: 253-257.

Jaim-Etcheverry, G., and L. M. Zieher (1971) Permanent depletion of peripheral norepinephrine in rats treated at birth with 6-hydroxydopamine. Eur. J. Pharmacol. 13: 272-276.

Johnson, E. M., Jr., and F. O'Brien (1976) Evaluation of the permanent sympathectomy produced by the administration of guanethidine to adult rats. J. Pharmacol. Exp. Ther. 196: 53-61.

Johnson, E. M., R. A. Macia, R. Y. Andres, and R. A. Bradshaw (1979) The effects of drugs which destroy the sympathetic nervous system on the retrograde transport of nerve growth factor. Brain Res. 171: 461-472.

Johnson, E. M., P. D. Gorin, L. D. Brandeis, and J. Pearson (1980) Dorsal root ganglion neurons are destroyed by exposure in utero to maternal antibodies to nerve growth factor. Science 210: 916-918.

Johnson, M., D. Ross, M. Meyers, R. Ress, R. Bunge, E. Wakshull, and H. Burton (1976) Synaptic vesicle cytochem- 
istry changes when cultured sympathetic neurones develop cholinergic interactions. Nature (Lond.) 262: 308-310.

Johnson, M. I., C. D. Ross, M. Meyers, E. J. Spitznagel, and R. P. Bunge (1980) Morphological and biochemical studies of the development of cholinergic properties in cultured sympathetic neurons. I. Correlative changes in properties in choline acetyltransferase and synaptic vesicle cytochemistry. J. Cell Biol. 84: 680-691.

Jonakait, G. M., J. Wolf, P. Cochard, M. Goldstein, and I. B. Black (1979) Selective loss of noradrenergic phenotype characters in neuroblasts of the rat embryo. Proc. Natl. Acad. Sci. U. S. A. 76: 4683-4686.

Jonakait, G. M., M. C. Bohn, K. Markey, M. Goldstein, and I. B. Black (1981) Elevation of maternal glucocorticoid hormones alters neurotransmitter phenotypic expression in embryos. Dev. Biol. 88: 288-296.

Jonsson, G., and C. Sachs (1972) Neurochemical properties of adrenergic nerves regenerated after 6 -hydroxydopamine. J. Neurochem. 19: 2577-2585.

Kessler, J. A., and I. B. Black (1980) Nerve growth factor stimulates the development of substance $P$ in sensory ganglia. Proc. Natl. Acad. Sci. U. S. A. 77: 649-652.

Kessler, J. A., and I. B. Black (1981) Nerve growth factor stimulates development of substance $\mathrm{P}$ in the embryonic spinal cord. Brain Res. 208: 135-145.

Kessler, J. A., P. Cochard, and I. B. Black (1979) Nerve growth factor alters the fate of embryonic neuroblasts. Nature (Lond.) 280: 141-142.

Kessler, J. A., W. O. Bell, and I. B. Black (1983a) Substance P levels differ in sympathetic target organ terminals and ganglion perikarya. Brain Res. 258: 144-146.

Kessler, J. A., W. O. Bell, and I. B. Black (1983) Interactions between the sympathetic and sensory innervation of the iris. J. Neurosci., 3: 301-307.

Knyihar, E., K. Ristovsky, G. Kalman, and B. Csillik (1969) Chemical sympathectomy: Histochemical and submicroscopical consequences of 6-hydroxydopamine treatment in the rat iris. Experientia 25: 518-520.

Landis, S. C. (1980) Developmental changes in the neurotransmitter properties of dissociated sympathetic neurons: a cytochemical study of the effects of medium. Dev. Biol. 77 : 348-361.

Landis, S. C., and D. Keefe (1983) Evidence for neurotransmitter plasticity in vivo: Developmental changes in properties of cholinergic sympathetic neurons. Dev. Biol. 98: 349372.

Letourneau, P. C. (1978) Chemotactic response of nerve fiber elongation to nerve growth factor. Dev. Biol. 66: 183-196.

Levi-Montalcini, R. (1982) Developmental neurobiology and the natural history of nerve growth factor. Annu. Rev. Neurosci. 5: $341-362$.

Levi-Montalcini, R., L. Aloe, E. Mugnaini, F. Oesch, and H. Thoenen (1975) Nerve growth factor induces volume increase and enhances tyrosine hydroxylase synthesis in chemically axotomized sympathetic ganglia of newborn rats. Proc. Natl. Acad. Sci. U. S. A. 72: 595-599.

Lorez, H. P., H. Kuhn, and G. Bartholini (1975) Degencration and regeneration of adrenergic nerves in mesenteric blood vessels, iris and atrium of the rat after 6-hydroxydopamine injection. J. Neurocytol. 4: 157-176.

Malmfors, T., and C. Sachs (1968) Degeneration of adrenergic nerves produced by 6 -hydroxydopamine. Eur. J. Pharmacol. 3: 89-92.

Manning, P. T., J. H. Russell, and E. M. Johnson, Jr. (1982) Immunosuppressive agents prevent guanethidine-induced destruction of rat sympathetic neurons. Brain Res. 241: 131143.

Manning, P. T., C. W. Powers, R. E. Schmidt, and E. M. Johnson, Jr. (1983) Guanethidine-induced destruction of pe- ripheral sympathetic neurons occurs by an immune-mediated mechanism. J. Neurosci. 3: 714-724.

Menesini Chen, M. G., J. S. Chen, and R. Levi-Montalcini (1978) Sympathetic nerve fibers ingrowth in the central nervous system of neonatal rodents upon intracerebral NGF injections. Arch. Ital. Biol. 116: 53-84.

Miller, A., M. Costa, J. B. Furness, and I. W. Chubb (1981) Substance $\mathrm{P}$ immunoreactive sensory nerves supply the rat iris and cornea. Neurosci. Lett. 23: 243-249.

Mitchell, J. R., and J. A. Oates (1970) Guanethidine and related agents. I. Mechanism of the selective blockade of adrenergic neurons and its antagonism by drugs. J. Pharmacol. Exp. Ther. 172: 100-107.

Patterson, P. H. (1978) Determination of autonomic transmitter functions. Annu. Rev. Neurosci. 1: 1-17.

Polak, J. M., and S. R. Bloom (1981) The peripheral substance P-ergic system. Peptides 2 (Suppl. 2): 133-148.

Potter, D. D., S. C. Landis, and E. J. Furshpan (1981) Adrenergic-cholinergic dual-function in cultured sympathetic neurones of the rat. Ciba Found. Symp. 83: 123-138.

Ross, M., S. Lofstrandh, P. D. Gorin, E. M. Johnson, and J. P. Schwartz (1981) Use of an experimental autoimmune model to define nerve growth factor dependency of peripheral and central substance P-containing neurons in the rat. .J. Neurosci. 1: 1304-1311.

Saner, A., and H. Thoenen (1971) Model experiments on the molecular mechanism of the action of 6-hydroxydopamine. Mol. Pharmacol. 7: 147-154.

Siegel, R. E., M. Schwab, and S. C. Landis (1982) Developmental changes in the neurotransmitter properties of cholinergic sympathetic neurons in vivo. Soc. Neurosci. Abstr. 8: 7.

Snell, R. S., and J. R. Garrett (1958) The effect of postganglionic sympathectomy on the histochemical appearances of cholinesterase in the nerves supplying the submandicular and sublingual salivary glands of the rat. Z. Zellforsch. 48: 201-214.

Teitelman, G., C. Baker, T. Joh, and D. Reis (1979) Appearance of catecholamine synthesizing enzymes during development of rat sympathetic nervous system: Possible role of tissue environment. Proc. Natl. Acd. Sci. U. S. A. 76: 509-513.

Tervo, K., T. Tervo, L. Eranko, O. Eranko, and A. C. Cuello (1981) Immunoreactivity for substance $\mathbf{P}$ in the Gasserian ganglion, ophthalmic nerve, and anterior segment of the rabbit eye. Histochem. J. 13: 435-443.

Thibault, J., D. Vidal, and F. Gros (1981) In vitro translation of mRNA from rat pheochromocytoma tumors, characterization of tyrosine hydroxylase. Biochem. Biophys. Res. Commun. 99: 960-968.

Thoenen, H., and Y. -A. Barde (1980) Physiology of nerve growth factor. Physiol. Rev. 60: 1284-1335.

Thoenen, H., and J. P. Tranzer (1968) Chemical sympathectomy by selective destruction of adrenergic nerve endings with 6-hydroxydopamine. Naunyn Schmiedebergs Arch. Pharmacol. 261: 271-288.

Tiffany-Castiglioni, E., R. P. Saneto, P. H. Proctor, and J. R. Perez-Polo (1982) Participation of active oxygen species in 6-hydroxydopamine toxicity to a human neuroblastoma cell line. Biochem. Pharmacol. 31: 181-188.

Tornqvist, K., A. Mandahl, S. Leander, I. Lorén, R. Håkanson, and F. Sundler (1982) Substance P-immunoreactive nerve fibres in the anterior segment of the rabbit eye. Cell Tissue Res. 222: 467-477.

Tranzer, J. P., and H. Thoenen (1968) An electron microscopic study of selective, acute degeneration of sympathetic nerve terminals after administration of 6-hydroxydopamine. Experientia 24: $155-156$.

Uno, H., and W. Montagna (1975) Catecholamine-containing nerve terminals of the eccrine sweat glands of macaques. Cell Tissue Res. 158: 1-13. 